\title{
低 $\mathrm{Ni}-\mathrm{Cr}$ 鋳鉄における $\mathrm{Ni} の$ 影響についで
}

$$
\text { 井川 博** 近藤 明 }{ }^{* *} \text { 土居定雄 }{ }^{* *}
$$

Hiroshi Ikawa, Akira Kondo and Sadao Doi : Effect of $\mathrm{Ni}$ on Low $\mathrm{Ni}-\mathrm{Cr}$ Cast Iron. On the low $\mathrm{Ni}-\mathrm{Cr}$ cast iron containing approximately 1.0 to $3.0 \% \mathrm{Ni}$ and 0.5 to $1.5 \% \mathrm{Cr}$, the effect of the $\mathrm{Ni}$ contents on the thermal expansion, growth, resistance to oxidation and microstructure, which are the basic properties of low alloy heat-resisting cast iron, were studied. The results obtained are as follows:

(1) Mechanical properties of cast iron containing approximately $2.0 \% \mathrm{Ni}$ and $1.5 \% \mathrm{Cr}$ are good. When the $\mathrm{Ni}$ content is increased to about $3.0 \%$, almost same values are obtained in relation to the tensile strength irrespective of the $\mathrm{Cr}$ content.

(2) Cast iron containing approximately $2.0 \% \mathrm{Ni}$ and $1.5 \% \mathrm{Cr}$ indicates the lowest thermal expansion value. When $\mathrm{Ni}$ content is increased to about $3.0 \%$, a tendency of expansion is recognized.

(3) Cast iron containing approximately $2.0 \% \mathrm{Ni}$ and $1.5 \% \mathrm{Cr}$ also indicates the lowest value in growth rate. The growth rate becomes clearly larger with increasing $\mathrm{Ni}$ content.

(4) A similar tendency is observed between the resistance to oxidation and at the growth rate, but the effect of the $\mathrm{Ni}$ content on the weight gain is somewhat stronger than that of the $\mathrm{Cr}$ content.

(5) Plain cast iron is poor in thermal expansion, growth rate, and resistance to oxidation. At some testing temperatures, however, the above cast iron is superior to cast iron containing a small amount of $\mathrm{Ni}$ and $\mathrm{Cr}$.

(6) On the microstructure of cast iron containing approximately 1.0 to $2.0 \% \mathrm{Ni}$, graphite becomes smaller and cementite increases with increasing $\mathrm{Cr}$ content. When the $\mathrm{Ni}$ content is increased to about $3.0 \%$, graphite becomes larger and cementite decreases to some extent.

It is concludes that the $\mathrm{Ni}$ content ranging from 1.0 to $2.0 \%$ acts effectively on the basic properties of low alloy heat-resisting cast iron in the range of $\mathrm{Cr}$ contents from 0.5 to $1.5 \%$, but an undesirable effect appears when the $\mathrm{Ni}$ content is increased to about $3.0 \%$.

(Received June 30, 1966)

\section{I. 緒曹}

普通鋳鉄に少量の $\mathrm{Ni}, \mathrm{Cr}$ 箪独または複合添加した低 合金鋳鉄の基本的な性質，すら方ち，熱膨張，成長性，耐 酸化性などについては一部を報告した(1)(2)．Ni，Crをそれ ぞれ単独に添加した場合には，上記諸性質におよぼす添加 元素の影響が明らかに認められたが， Ni，Cr 複合添加し た場合については，Ni添加量が約 $0.5 \%$ と $1.5 \%$ の采 列であつたため，それがどのような影響を拉よばすかは明 瞭には認められなからた。よつて本報では，Cr 添加量を 前報(1) と同じく約 $0.5,1.0,1.5 \%$ とし， Ni 添加量を約 1.0 , $2.0 ， 3.0 \%$ として，Ni，Cr 複合添加したものにつき上記 の諸性質をしらべ, Niがそれらにどのよ5な影響を㧍よ 将すかを明らかにした。

\section{II. 試料および実験方法}

試料の溶製, 機械的試験, 熱嘭張試験, 成長試験および 耐酸化性試験などについては，前報(1) と全く同じ方法で行 なつた.

顕徽鏡組織については，鋳放しのままのものと成長試験

** 愛媛大学 工学部冶金学科 (Department of Metallurgy, Faculty of Engineering, Ehime University, Matsuyama)

* 1966 年 4 月本会東京大会に発表

（1）井川, 大西, 近藤, 土居: 本誌, 30 (1966), 274.

(2) 井川, 近藤, 土居: 1965 年 10 月 本会福岡大会に発 表.
を行なつたのちのものとについて，黒鉛の形状と分布状態 ならびに素地の組織を観察した。

\section{III.実験結果および考察}

\section{1. 化学組成と機械的性翼}

Table 1 亿溶製した 10 種類の試料の化学組成々機械的 性質とを示す。化学組成については，Ni，Or ともに緒言で 述べた目標成分からは多少のずれを生じた．引張強さにつ いては，Cr添加量が一定の場合，Ni が增すにしたがつて それは大きくなる。京た， $\mathrm{Ni}$ 添加量が約 $3 \%$ の試料 No. 23, 24, 25 亿扔いては, $\mathrm{Cr}$ 添加量 0.5 1.5\% の籁囲では, 引張強さにそれほど大きな差は認められない，ただし，硬 さにはかなりの変化が認められる。

\section{2. 熱㤸張試験}

Fig.1〜3 亿実験結果の 代表的なるのを示す．合金元素 の添加されないNo.0は著しく大きな膨張を示す（前報(1) の試料 No.1 にほぼ同じ)が，合金元素の添加されたすのは 試料 No.0にくらべて膨張は小さくなる. Ni 涯加量が約 $1 \%$ と $2 \%$ では Crの影響が大きく，膨張は小さくなる (Fig.1，2).これに反して,Ni 添加量が約 3\%になると(試 料 No.23，24，25) 膨張の傾向が認められる (Fig.3)．これ らの結果上り熱膨張試験飞执いては, 試料 No.21 がすつ とも膨張しがたい。また，Cr 添加量が増すにしたがつて 
変態温度は上畀し，Niが增すにしたがってそれは下降す＼cjkstart伸びる示したが，陚料 No.0 と No.14 とはそれがいくぶん るとい5一般的傾向 ${ }^{(3)}$ が明らかに認められた。

大きいことが認められた。 $800{ }^{\circ} \mathrm{C}$ に繰り返し加熱した場合

Table 1 Chemical composition and mechanical properties of cast irons.

\begin{tabular}{|c|c|c|c|c|c|c|c|c|c|c|}
\hline \multirow{2}{*}{$\begin{array}{c}\text { Specimen } \\
\text { No. }\end{array}$} & \multicolumn{7}{|c|}{ Chemical composition $(\%)$} & \multicolumn{3}{|c|}{ Mechanical properties } \\
\hline & $\mathrm{C}$ & $\mathrm{Si}$ & $\mathrm{Mn}$ & $\mathrm{P}$ & $S$ & $\mathrm{Ni}$ & $\mathrm{Cr}$ & $\begin{array}{l}\text { Tensile strength } \\
\left(\mathrm{kg} / \mathrm{mm}^{2}\right)\end{array}$ & $\begin{array}{l}\text { Deflection } \\
(\mathrm{mm})\end{array}$ & $\begin{array}{l}\text { Hardness } \\
(\mathrm{HB})\end{array}$ \\
\hline $\begin{array}{r}0 \\
14 \\
15 \\
16 \\
19 \\
20 \\
21 \\
23 \\
24 \\
25\end{array}$ & $\begin{array}{l}3.38 \\
3.37 \\
3.35 \\
3.38 \\
3.31 \\
3.38 \\
3.19 \\
3.10 \\
3.26 \\
3.35\end{array}$ & $\begin{array}{l}2.03 \\
1.98 \\
1.88 \\
1.87 \\
1.82 \\
1.87 \\
1.92 \\
1.92 \\
1.96 \\
1.91\end{array}$ & $\begin{array}{l}0.59 \\
0.56 \\
0.57 \\
0.55 \\
0.59 \\
0.60 \\
0.58 \\
0.59 \\
0.58 \\
0.57\end{array}$ & $\begin{array}{l}0.087 \\
0.091 \\
0.084 \\
0.089 \\
0.079 \\
0.084 \\
0.079 \\
0.092 \\
0090 \\
0.081\end{array}$ & $\begin{array}{l}0.025 \\
0.022 \\
0.022 \\
0.028 \\
0.027 \\
0.035 \\
0.027 \\
0.026 \\
0.032 \\
0.032\end{array}$ & $\begin{array}{l}0 \\
0.94 \\
0.92 \\
0.88 \\
2.17 \\
1.99 \\
2.29 \\
3.44 \\
3.42 \\
3.25\end{array}$ & $\begin{array}{r}0 \\
0.50 \\
0.92 \\
1.38 \\
048 \\
0.92 \\
1.36 \\
0.49 \\
0.90 \\
1.34\end{array}$ & $\begin{array}{l}21.1 \\
23.7 \\
28.2 \\
31.8 \\
26.1 \\
29.5 \\
33.9 \\
33.1 \\
32.5 \\
36.2\end{array}$ & $\begin{array}{l}2.0 \\
2.0 \\
1.5 \\
1.8 \\
2.0 \\
1.8 \\
1.5 \\
1.9 \\
1.3 \\
1.5\end{array}$ & $\begin{array}{l}183 \sim 195 \\
205 \sim 209 \\
235 \sim 252 \\
273 \sim 321 \\
223 \sim 229 \\
255 \sim 262 \\
302 \sim 331 \\
262 \sim 273 \\
269 \sim 277 \\
307 \sim 342\end{array}$ \\
\hline
\end{tabular}

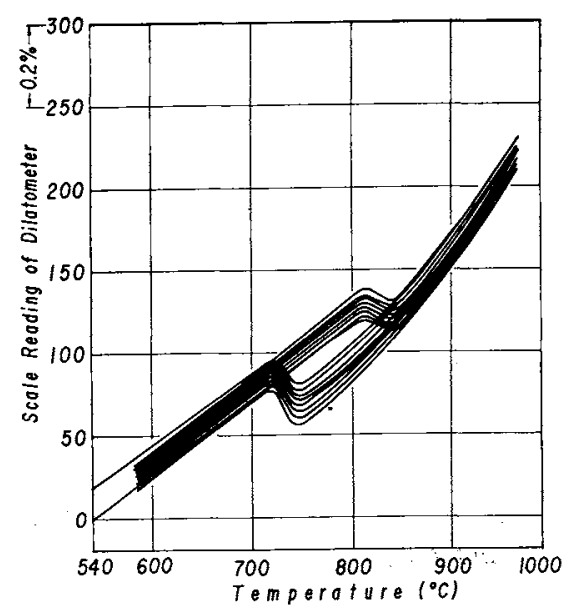

Fig.1 Dilatation curves of specimen No.16 (in vacuum). Repeated heating temperature range: $550^{\circ} \sim 950$ ${ }^{\circ} \mathrm{C}$. Heating and cooling rate: $10^{\circ} \mathrm{C} / \mathrm{min}$.

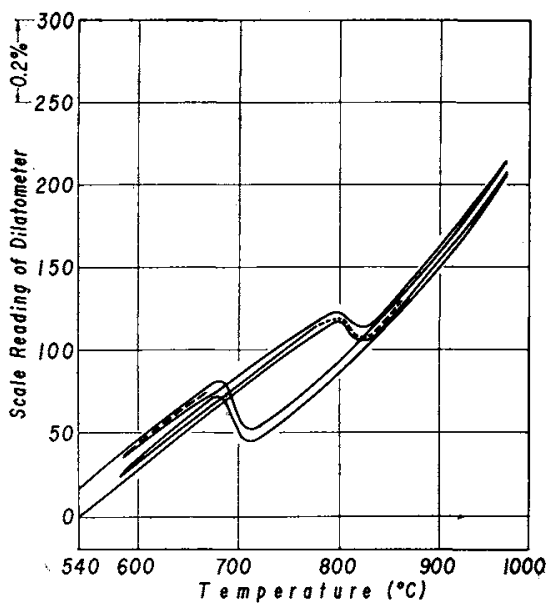

Fig.2 Dilatation curves of specimen No.21 (in vacuum). Repeated heating temperature range: $550^{\circ} \sim 950$ ${ }^{\circ} \mathrm{C}$. Heating and cooling rate: $10^{\circ} \mathrm{C} / \mathrm{min}$.

\section{3. 成 長 試 験}

Fig.4〜3に実験結果の代表的なるのを示す. $650^{\circ} \mathrm{C} に$ 繰り返し加熱した場合，ほとんどの試料は約 $0.5 \%$ 程度の

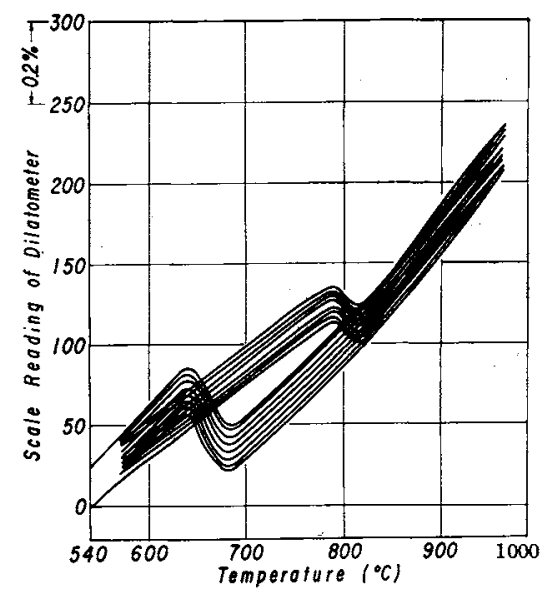

Fig.3 Dilatation curves of specimen No.25 (in vacuum). Repeated heating temperature range: $550^{\circ} \sim 950$ ${ }^{\circ} \mathrm{C}$. Heating and cooling rate: $10^{\circ} \mathrm{C} / \mathrm{min}$.

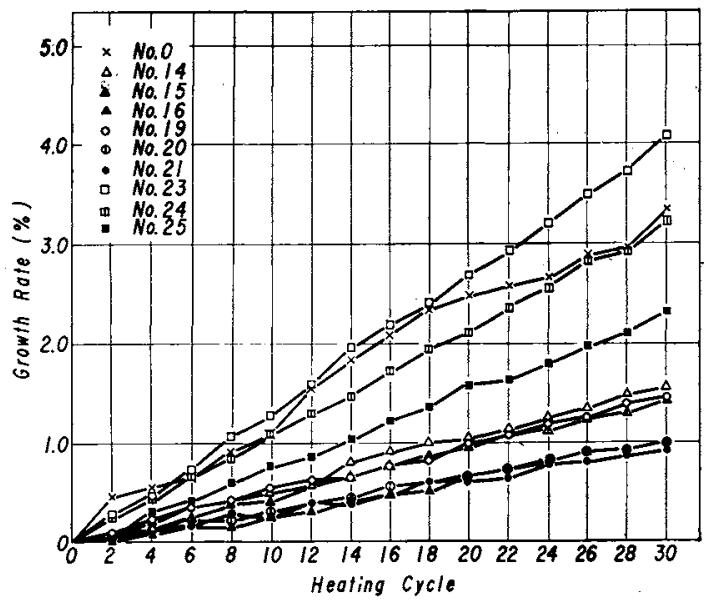

Fig.4 Results of growth test of cast irons cyclic heated for $3 \mathrm{hr}$ at $800^{\circ} \mathrm{C}$.

(Fig.4)，試料 No.16，20，21 の伸びは小さい值を示す. $950^{\circ} \mathrm{C}$ に繰り返し加熱した場合 (Fig.5)は，試験温度が高い

(3) W.Hume-Rothery: J.Iron and Steel Inst., 203 (1965), 1185 . 
ため陚料の伸びが大きく，成長の傾向が明りように認めら れる.この傾向は $800^{\circ} \mathrm{C}$ (Fig.4) の場合とは添同じである.

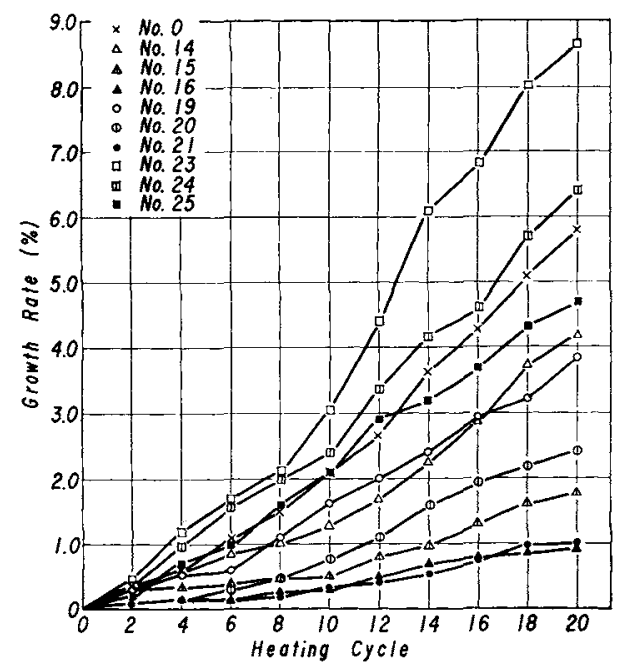

Fig.5 Results of growth test of cast irons cyclic heated for $3 \mathrm{hr}$ at $950^{\circ} \mathrm{C}$.

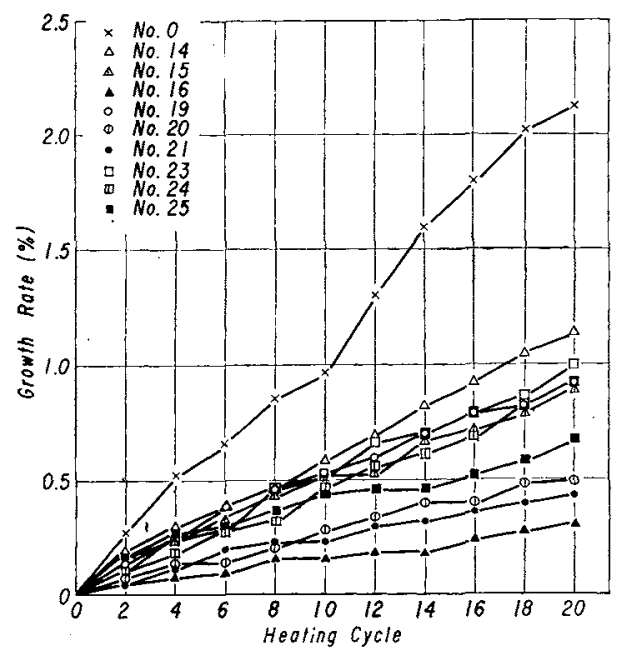

Fig.6 Results of growth test of cast irons cyclic heated for $3 \mathrm{hr}$ at $950^{\circ} \mathrm{C}$ in argon.

Fig.6 はアルゴン 気流中 $(150 \mathrm{cc} / \mathrm{min})$ に扮ける実駼結果で ある。これはふん肃気の相違が成長にどの上5な影響を招 よぼすかをしらべるために行なつたものである。图から明 らかなよ5に，試料 No.0が著しく大きな伸びを示すのに 対し，Ni，Cr を添加した試料はすべて約 $1 \%$ 以下の小さい 伸びを示す，Fig.6に拈けるとれぞれの試料の成長の傾向 は，Fig.4，5に扮けるとほ注同じである，また，Ni と Cr とは成長に対してたがいに相反する作用が認められている が(2)，Cr 添加量一定の場合， Ni 添加量が約 $1 \%$ と $2 \%$ で は著しい変化は認められない，ただし，Ni添加量が約 $3 \%$ になると，それの黒鉛化を助長する作用 ${ }^{(4)}$ が大きく現われ てくる.

(4) W.C.Blotto: Iron Age, $164(1949), 88$.
4. 耐酸化性試験

Fig.7，8 に実験結果の代表的なるのを示す. $650^{\circ} \mathrm{C}$ に繰

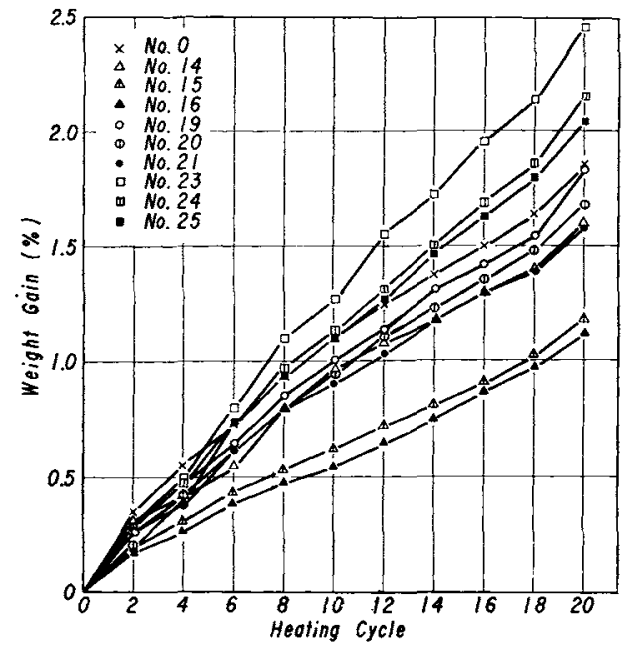

Fig.7 Results of resistance to oxidation test of cast irons cyclic heated for $2 \mathrm{hr}$ at $800^{\circ} \mathrm{C}$.

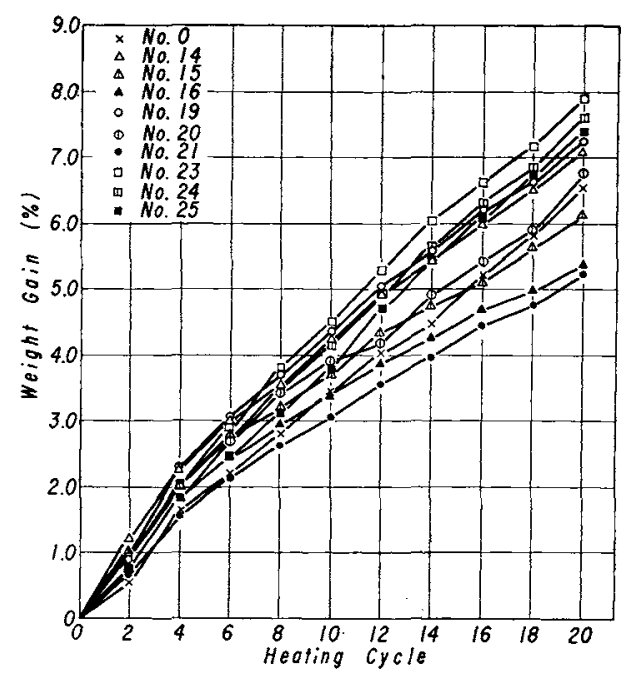

Fig. 8 Results of resistance to oxidation test of cast irons cyclic heated for $2 \mathrm{hr}$ at $950^{\circ} \mathrm{C}$.

り返し加熱した場合，合金元素の添加されたるのは，いず れも試料 No.0にくらべて耐酸化性はよくなつている。 く試料 No.16，21，26 は酸化增量が少なく，かつ汪汴同 じ値を示す. $800^{\circ} \mathrm{C}$ (Fig.7) と $950^{\circ} \mathrm{C}$ (Fig.8) 亿繰り返し加熱

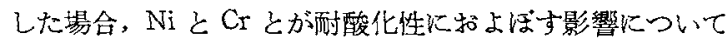
は成長試験の場合とほぼ同じ傾向を認めることができる。 $800^{\circ} \mathrm{C}$ の場合, $\mathrm{Ni}$ 添加量約 $3 \%$ のものは $\mathrm{Cr}$ 添加量 $0.5 \sim$ $1.5 \%$ の範囲では，いずれも試料 No.0より酸化增量が多 くなっている. $950^{\circ} \mathrm{C}$ の場合る，試料 No.15, 16, 21 を除 きいずれる試料 No.0 より酸化増量が多くなる、これらの 結果から耐酸化性試験に拈いては，成長試験の場合にくら べて Ni の作用がより大きいるのと考学られる。

\section{5. 顥 微 鏡 組}


Photo.1〜3に代表的な組織を示す. Photo.1 は鋳放しの されたものでは, 試料 No.21(Photo.1(a))に示すように黑

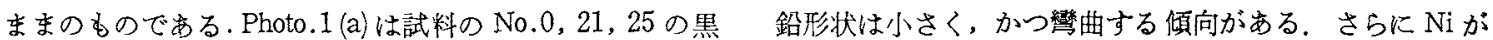

(a)

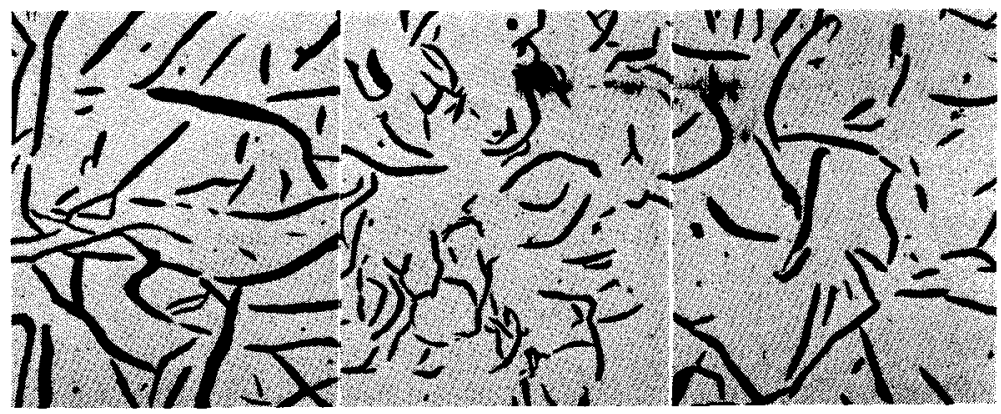

(b)

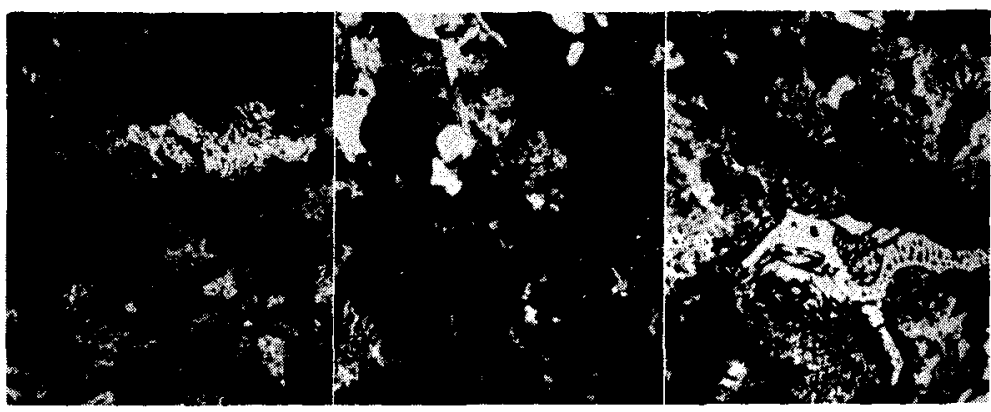

No. 0

No.21

No. 25

Photo.1 Microstructures of specimen No.0, No.21 and No.25 as cast.

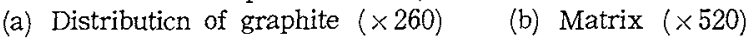
Etchant: $5 \%$ Nital.

(a)

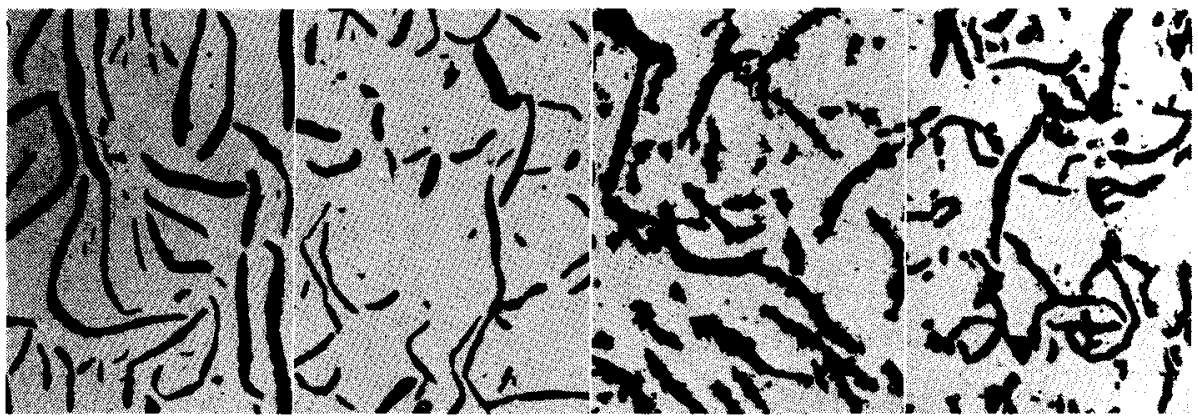

(b)

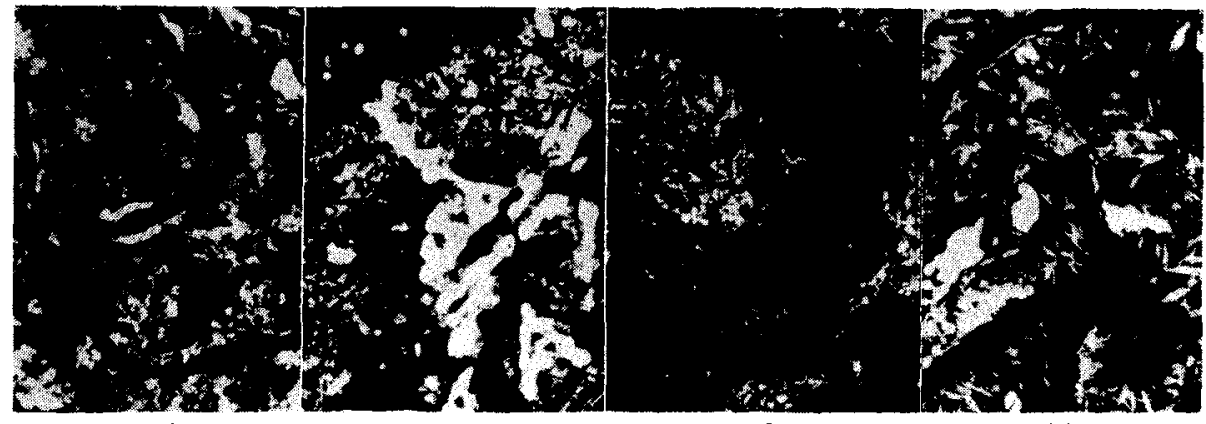

No. 0

No. 21

No.23

No. 24

Photo.2 Microstructures of specimen No.0, No.21, No.23 and No.24 after repeated heating for $3 \mathrm{hr}$ at $950^{\circ} \mathrm{C}$ in air.

$\begin{array}{ll}\text { (a) Distribution of graphite }(\times 260) & \text { (b) Matrix }(\times 520)\end{array}$ Etchant: $5 \%$ Nital.

鉛形状を示し，Photo.1(b)は同じくそれらの素地の組織志 示している. 試料 No.0 の黑鉛形状 (Photo.1(a)) について は,大きな片状黒鉛が認められる。しかし，合金元素の添加
添加されると，試料 No.25 (Photo.1(a)) K示す上5に黒鉛 形状は太く，かつ片状になる。試料 No.0 (Photo.1 (b))の 素地はパーライトであるが，合金元素の添加されたるので 
は, 試料 No.21，25(Photo.1(b))に示すよ5に七メンタイ 地 (Photo.3(b)) はフェライトで, 硬さはHv 201 と 236 を トが認められる.Ni 添加量が約 $3 \%$ の試料 No.25 (Photo. 1

示寸. 試料 No.14の素地 (Photo.3(b)) はパーライトとフ

(a)

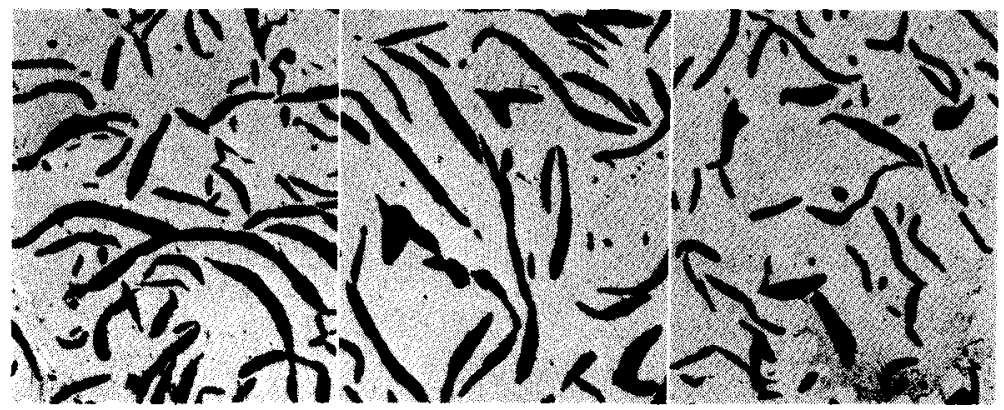

(b)

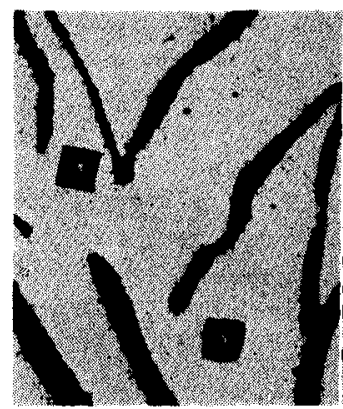

No. 0

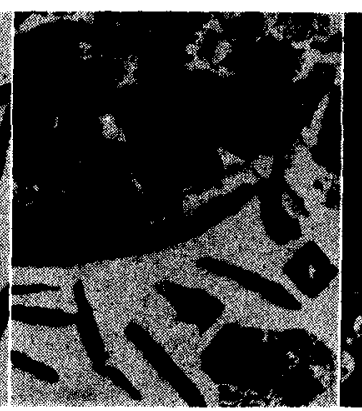

No. 14

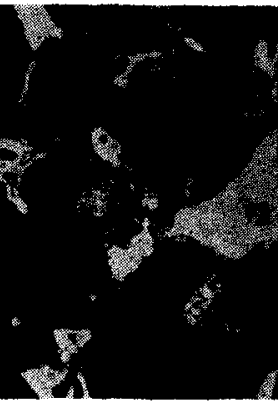

No.21

Photo.3 Microstructures of specimen No.0. No.14 and No.21 after repeated heating for $3 \mathrm{hr}$ at $950^{\circ} \mathrm{C}$ in argon.
(a) Distribution of graphite $(\ltimes 260)$
Etchant: $5 \%$ Nital.

(b)にははマルテンサイトが認められる

Photo. 2 は $950^{\circ} \mathrm{C}$ で成長試験を行なつたすのである. Photo.2 (a) 敦料 No.0,21, 23, 24 の黑鉊形状を示し, Photo.2 (b) は同じくそれらの素地の組織を示している. 試 料 No.21 の黑鉛形状 (Photo.2(a)) については, 鋳放しのま まのものよりいくぶん太くなつている，Ni 添加量が約 $3 \%$ の試料 No.23, 24 の黑鉛形状 (Photo.2(a)) については, 黑 鉛の周辺に突起を生じている。この現象は前報 ${ }^{(1)}$ と同じよ 5 に考察される。試料 No.0 の素地(Photo.2(b)) はパーラ イトとフェライトからなるが，合金元素の添加されたるの では, 陚料 No.21，23，24(Photo.2(b)) に示すよ 5 に マ テンサイトが認められる。試料 No.21, 24 (Photo.2 (b)) に はセメンタイトも生じているが，試料 No.23(Photo.2(b)) にはそれは認められない。これは Niが多くCr が少ない ためにNiの黑鉛化作用が強〈現われたものと考えられる。

Photo. 3 はアルゴン 気流中 $\left(950^{\circ} \mathrm{C}\right)$ で成長試験を行なつ たるので方る。Photo.3(a) は試料 No.0, 14, 21 の黑鉛形 状を示し,Photo.3(b)は同じくそれらの素地の組織を示し ている，組織中の王こんは：ミクロビッカース硬さ（荷重 $50 \mathrm{~g}$ )を測定した場合のものである、黒鉛形状は鋳放しの ままのるのよりいくぶん太くなつている. 試料 No.0の素

ェライトからなる。パーシイトの 硬さはHv336と 326 を示す。試 料 No.21 (Photo.3(b)) 双合金元素 が多いためセメンタイトが認めら れる。 セメンタイトの硬さは $\mathrm{Hv}$ 558 各示し，パーライトのそれは Hv 353 と 358 を示す.

$$
\text { IV. 結喜 }
$$

以上の実験結果より烈膨張，成 長性，酎酸化性，顕微鏡組織を通 じてCr は前垠(1) と同じようにい ずれもよい影響を与光る。 Ni は添 加量が約 $1 \%$ と $2 \%$ ではよい影響 定与古るが，約 $3 \%$ になるとか党 つてこのましくない影響が現われ る。これらな要約するとつぎのよ らである。

(1) 機戌的性質については, Ni, Crが增すにしたがつて引張強さ， 硬さは増大する。しかし， $\mathrm{Ni}$ 約 $3 \%$ では引張強さには注 とんど変化が認められない。

（2）熱膨張試験については, $\mathrm{Ni}$ 䄪 $1 \%$ と $2 \%$ では $\mathrm{Cr}$ 添 加量が增すにしたがつて膨張は小さくなる。 Ni 約 $3 \%$ に なると，同一Cr 添加量では，膨張は大きくなる。

(3) 成長試験については，Ni 添加量が增すにしたがつ て成長率は大きくなり，Cr 添加量が增すにしたがつてそ れは小さくなる。試料 No.16 と No.21 の成長率は小さく。 がつ核洞じ値を示す。

（4）耐酸化性試験については，成長試験とほぼ同じ㑯向 を示豆が，成長試験の場合にくらべて，Ni の影響は大き く現われる。試料 No.16 と No.21 は酎酸化性がよい。

(5) 合金元素の添加されない陚料 No.0 は熱膨張, 成長 性 $\left(650^{\circ} \mathrm{C}\right)$ ，酎酸化性 $\left(650^{\circ} \mathrm{C}\right)$ いずれも劣る。 ただし, 試験 温度によりては合金元素の添加されたものよりよい結果が えられる(Fig.5〜8)。

(6) 顕微鏡組織については, $\mathrm{Ni}$ 約 $1 \%$ と $2 \%$ では, $\mathrm{Cr}$ 添加量が增すにしたがつて黒鉛形状は小さくなり，七メン タイトは多くなる。しかし，Ni 約 $3 \%$ ては，黑鉛形状は 大きくなり，七メンタイトの量はいくぶん少なくなる。

終りに本研究を遂行するにあたり，熱心に実験に協力さ れた森岡哲郎工学士(当時学生)に感謝の意を表します。 